\title{
Exploring the Consequences of Gender Ideology_Work Discrepancies
}

\author{
Amy Kroska
}

Published online: 27 January 2009

(C) Springer Science + Business Media, LLC 2008

Erratum to: Sex Roles

DOI 10.1007/s11199-008-9552-x

Due to an error in production and through no fault of the author, Table 6 was erroneously typeset and inadvertently published in the original version of this article. The correct Table 6 is as follows:

Springer regrets the error.

The online version of the original article can be found at http://dx.doi. org/10.1007/s11199-008-9552-x.

A. Kroska $(\triangle)$

Department of Sociology, University of Oklahoma,

Kaufman Hall 331,

Norman, OK 73019, USA

e-mail: amykroska@ou.edu 


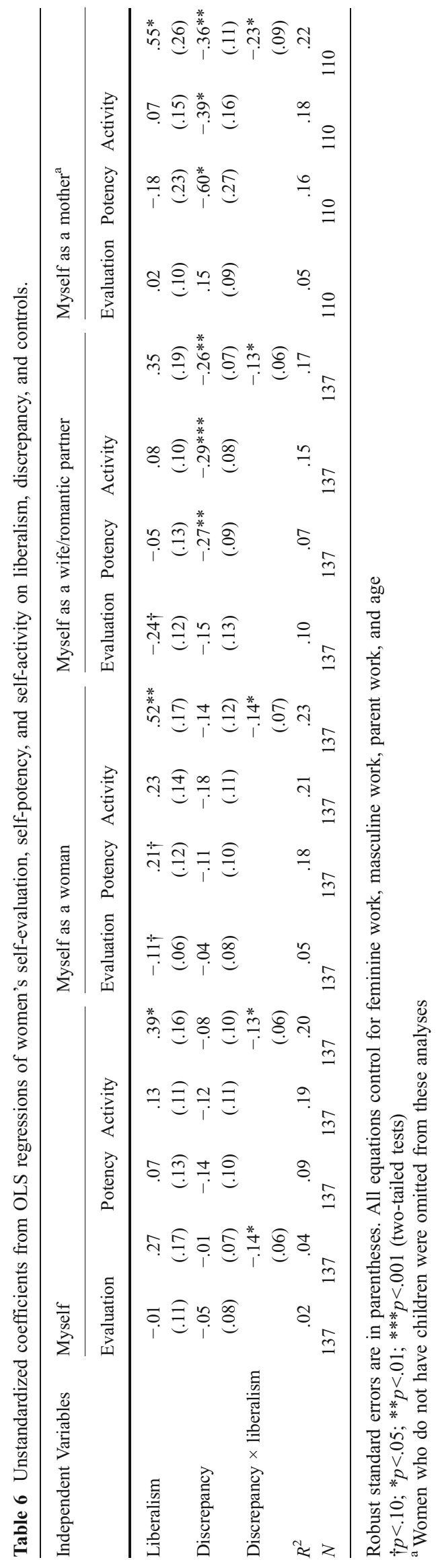

